\title{
Equity in Healthcare - Perspectives and Prospectives
}

\section{lan W R Anderson *}

Health care is one of the foremost issues affecting all countries in the world and the challenges of how to deliver effective and affordable health care concentrate the minds of politicians, professionals and the public globally.

With the recent surge in technological change, modern medicine promises to deliver standards of investigation and treatment which previous generations would have found bewildering, but they threaten to do so at a cost which could cripple even the strongest of economies.

Without doubt, the major challenge in the near and medium term will be how to cope with the scourge of noncommunicable disease: in particular, cancer care will prove an increasing problem for developing societies even more so than in the developed world. Metabolic problems and in particular, diabetes, are already a major emerging problem for health care systems and at the same time, an increasingly attractive market for big pharma.

These issues will be highlighted and there will be an opportunity to discuss the ways and means to cope with these problems in individual environments.

*Mr. Ian W R Anderson, President, Royal College of Physicians and Surgeons of Glasgow. 